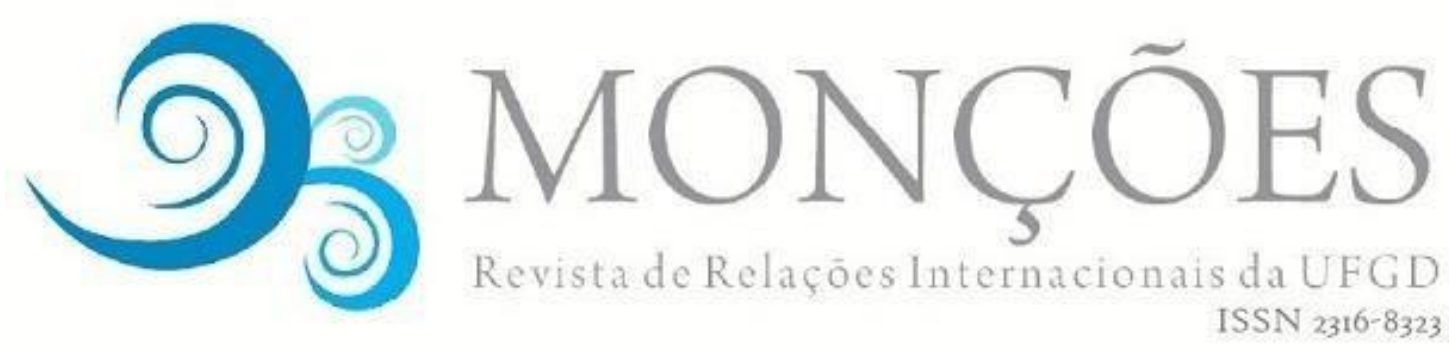

\title{
DIREITOS HUMANOS DAS MULHERES: UMA ANÁLISE SOBRE AS RECOMENDAÇÕES DO COMITÊ CEDAW/ONU AO ESTADO BRASILEIRO
}

\author{
CLAUDIA SANTOS \\ Mestre em Ciência Política pela Universidade Federal do Paraná (PPGCP/UFPR)
}

\begin{abstract}
ALEXSANDRO EUGENIO PEREIRA
Doutor em Ciência Política pela Universidade de São Paulo (USP). Docente dos Programas de Pós-Graduação em Ciência Política (PPGCP) e em Políticas Públicas (PPGPP) da Universidade Federal do Paraná.
\end{abstract}

RESUMO: O artigo analisará as recomendações do Comitê CEDAW ao Estado brasileiro. O Comitê é o mecanismo de monitoramento da Convenção sobre a Eliminação de todas as Formas de Discriminação contra a Mulher (CEDAW). Os Estados apresentam relatórios ao Comitê sobre o tratamento dos direitos humanos das mulheres dentro de seus territórios. Em paralelo, os atores não-estatais feministas apresentam relatórios alternativos com o propósito de subsidiar as atividades do Comitê CEDAW. Com base nos relatórios oficiais e nos relatórios alternativos, o Comitê apresenta recomendações aos Estados signatários da Convenção. Neste artigo, o objetivo será examinar o conteúdo das recomendações do Comitê endereçadas ao Estado brasileiro e verificar a compliance do Brasil em relação ao regime internacional estabelecido pela Convenção. Para desenvolver essa análise, serão apresentadas definições sobre regimes internacionais em geral e regimes internacionais de direitos humanos em particular. $\mathrm{Na}$ sequência, serão apresentados: (I) o funcionamento e o papel da CEDAW no cenário internacional; e (ii) seus princípios conforme relatados nos documentos oficiais. Em seguida, as recomendações do Comitê CEDAW ao Estado brasileiro serão examinadas contrastando com dados sobre o tratamento dos direitos humanos das mulheres no Brasil.

PALAVRAS-CHAVE: CEDAW; Direitos Humanos das mulheres; Brasil.

\section{HUMAN RIGHTS OF WOMEN: AN ANALYSIS OF THE RECOMMENDATIONS OF THE CEDAW COMMITTEE/UN TO THE BRAZILIAN STATE}

ABSTRACT: The article analyzeS recommendations of the CEDAW Committee to the Brazilian State. The Committee is the monitoring mechanism of the Convention on the Elimination of All Forms of Discrimination against Women (CEDAW). States report to the Committee treatment of women's human rights within their territories. In parallel, the non-state feminist actors present alternative reports for the purpose of subsidizing the activities of the CEDAW Committee. Based on official reports and alternative reports, the Committee presents recommendations to the signatory States of the Convention. In this article, the objective will be to examine the contents of the Committee's recommendations addressed to Brazil and verify the compliance of the Brazilian State in relation to the international regime established by the Convention. To develop this analysis, definitions will be presented on international regimes in general and international human rights regimes in particular. The following will be presented: the functioning and role of CEDAW 
in the international arena and its principles as reported in the official documents. Then, the recommendations of the CEDAW Committee to the Brazilian State will be examined in contrast to data on the treatment of the human rights of women in Brazil.

KEYWORDS: CEDAW; Human rights of women; Brazil.

\section{INTRODUÇÃO}

A Convenção sobre a Eliminação de todas as Formas de Discriminação contra a Mulher (Convention on the Elimination of All Forms of Discrimination against Women ou CEDAW) é um tratado de Direitos Humanos das Mulheres, no qual os Estados signatários se comprometem a cumprir seu conteúdo. A CEDAW faz parte da estrutura universal de Direitos Humanos da Organização das Nações Unidas (ONU) voltada para questões de gênero nas relações internacionais. De acordo com Shaheen Ali (2006), a CEDAW apresenta-se como um tratado voltado à promoção dos Direitos das mulheres, colocando-se contra a discriminação pautada no sexo, ainda tão comum nos valores culturais dos países.

$\mathrm{Na}$ sua organização interna, a CEDAW conta com um Comitê especializado cujo objetivo é monitorar o progresso da efetivação da Convenção nas normas e nas políticas adotadas pelos Estados signatários. O Comitê CEDAW solicita que os Estados enviem relatórios periódicos de quatro em quatro anos sobre seus avanços e dificuldades na implementação da Convenção. Conjuntamente, a sociedade civil organizada pode enviar um relatório alternativo, com o propósito de auxiliar as tarefas de verificação realizadas pelo Comitê.

O Comitê desempenha um papel limitado, mas relevante num contexto internacional caracterizado pela marginalização das questões de gênero na maioria dos Comitês de Direitos Humanos, conforme aponta Rebecca Cook (1994). Para a autora, a CEDAW seria uma exceção nesse contexto. O papel do Comitê é limitado pelas dificuldades de se produzir avanços na implementação 
do conteúdo da Convenção dentro dos Estados signatários. Por isso, é relevante desenvolver estudos empíricos sobre a realidade dos países no que se refere à efetividade dos direitos das mulheres. Neste artigo, procura-se observar qual é o conteúdo das recomendações apresentadas pelo Comitê ao Estado brasileiro. É necessário ressaltar que o Brasil apresentou uma das leis recentes mais importantes referentes aos Direitos Humanos das mulheres, a Lei Maria da Penha (Lei no 11.340/2006), tornando-se referência para outros países latinoamericanos. Nesse sentido, o caso brasileiro demanda estudos empíricos, capazes de verificar como o país procurou adequar sua legislação e suas políticas públicas ao conteúdo da CEDAW.

Sendo assim, o artigo analisará as recomendações do Comitê da CEDAW ao Estado brasileiro no período de 2003 a 2012. Nesse período, o Comitê elaborou três relatórios apresentando recomendações ao Brasil. O propósito específico é examinar o conteúdo dessas recomendações e verificar a compliance do Estado brasileiro em relação ao regime internacional estabelecido pela Convenção. Segundo Oran Young (1979), compliance ocorre quando o comportamento de um ator estatal corresponde ao cumprimento de prescrições estabelecidas pela instituição (ou regime internacional). Situações de noncompliance ocorrem quando o comportamento desse ator não segue essas prescrições (YOUNG, 1979). Em outros termos, é possível verificar em que medida um Estado procurou ajustar seu comportamento ao conteúdo de regimes internacionais.

Para apresentar esta análise, o artigo está dividido em três seções, além desta introdução e das considerações finais. Na primeira seção, serão apresentadas, em linhas gerais, definições sobre regimes internacionais e como a CEDAW se enquadra como regime da área de Direitos Humanos. Na segunda seção, serão apresentados o funcionamento e o papel da CEDAW no cenário internacional e seus princípios, conforme relatados nos documentos oficiais. $\mathrm{Na}$ terceira seção, as recomendações do Comitê CEDAW ao Estado brasileiro serão apresentadas e examinadas em contraste com dados sobre o tratamento dos Direitos Humanos das mulheres no Brasil. 


\section{A DEFINIÇÃO TEÓRICA DE REGIMES INTERNACIONAIS, O REGIME INTERNACIONAL DE DIREITOS HUMANOS E A CEDAW.}

A CEDAW pode ser caracterizada como um regime internacional. Para isso, esta seção apresentará, inicialmente, a definição mais usual de regimes, sistematizada por Stephen Krasner (2012) na coletânea de artigos organizada por ele na International Organization, em 1982. Segundo Stephen D. Krasner, regimes internacionais podem ser definidos "como princípios, normas e regras implícitos ou explícitos e procedimentos de tomada de decisões de determinada área das relações internacionais em torno dos quais convergem as expectativas dos atores" (KRASNER, 2012, p.94). Complementando a explicação do conceito de regimes, Krasner salienta a importância da distinção entre princípios e normas, de um lado, e regras e procedimentos, de outro. Os princípios e as normas são as características básicas do regime cuja alteração compromete a sua natureza. Regras e procedimentos, por sua vez, podem ser alterados dentro de um regime, pois estão amparados pelos princípios e normas.

Uma das características dos regimes, segundo Krasner, é o seu caráter abrangente. É o caso, por exemplo, do regime internacional de Direitos Humanos dentro do qual estão inseridas as temáticas das mulheres, das crianças e dos refugiados, entre outras. Krasner ressalta, também, que os regimes não mudam "com cada alteração de poder ou interesses dos Estados" (KRASNER, 2012, p.94) e tem como objetivo facilitar acordos no longo prazo.

Oran Young (1982) prefere tratar os regimes como instituições sociais complexas. Essas instituições visam pautar as ações dos Estados, com o propósito de conduzir a convergência das expectativas de atores estatais autointeressados em determinadas temáticas da política internacional. Ele salienta que os regimes refletem e, ao mesmo tempo, seriam "produtos do comportamento de um grande número de indivíduos ou grupos" (YOUNG, 1982, p.280; tradução livre - [...] products of the behavior of a large number of individuals or groups). E como instituições sociais complexas, são passíveis de transformações, mesmo com certa resistência dos atores envolvidos. Quando 
em funcionamento, são capazes, também, de influenciar os resultados da interação dos atores estatais.

Donnelly (1986) complementa essa abordagem ao dizer que os regimes internacionais existem quando Estados, "a fim de evitar os custos de uma ação nacional descoordenada, podem concordar (mais ou menos explicitamente) com normas e procedimentos para regular suas interações" (DONNELLY, 1986, p.601-602; tradução livre - [...] in order to avoid the costs of uncoordinated national action, are able to agree (more or less explicitly) on norms or procedures to regulate their interactions). Os regimes geram limitações à soberania de um Estado em determinada área, mas seu propósito é reduzir os custos da anarquia internacional do sistema interestatal (DONNELLY, 1986).

Para Krasner (2012), o enfraquecimento de um regime pode ocorrer de duas formas. A primeira seria pela incoerência das regras e procedimentos em relação aos princípios e normas. A segunda é resultante de práticas em desacordo com os princípios e normas de determinado regime. Em termos empíricos, essa segunda forma se manifesta, por exemplo, no regime internacional de Direitos Humanos das mulheres. O enfraquecimento do regime resultaria das práticas ainda relutantes de Estados-Partes em alterar legislações e condutas culturais sexistas e racistas contra as mulheres por meio de leis e ações políticas e civis, capazes de resguardar os Direitos Humanos delas. Para Young (1989), este fenômeno é típico de regimes de ordem espontânea, como o de meio ambiente e o de Direitos Humanos, pois a mudança social mostra-se mais resistente nesses casos. Para que possam determinar o comportamento dos atores estatais, regimes de ordem espontânea pressupõem uma mudança cultural e não apenas jurídica. Para funcionar de forma mais efetiva, a CEDAW depende de uma mudança maior no conjunto de valores e práticas que orienta a ação dos Estados.

O regime internacional contemporâneo de Direitos Humanos possui relação direta com a jurisdição nacional dos Estados. Donnelly (1986) explica que a Declaração Universal de Direitos Humanos rege as normas desse regime e é aceita mundialmente como uma norma capaz de impor sanções aos Estados que a violam, pelo menos em tese. Porém, na realidade, a Declaração esbarra 
na soberania plena dos Estados "para determinar a adequação de suas realizações" (DONNELLY, 1986, p.608; tradução livre- [...] to determine the adequacy of its achievements). É importante ressaltar que tratados e convenções podem impor obrigações legais, desde que o Estado aceite, voluntariamente, fazer parte deles e ratificá-los ${ }^{1}$.

Donnelly (1986, p.603-604) categoriza os regimes internacionais em quatro tipos: 1) Normas internacionais autoritativas: correspondem às normas internacionais vinculativas. O caráter vinculante de uma norma internacional permite a aplicação de sanções aos Estados-Partes que não cumprem suas regras; 2) Normas internacionais com exceções nacionais auto-selecionadas: geralmente se caracterizam por serem vinculativas, mas que, no entanto, permitem que os Estados-Partes "optem por" ratificar um tratado com reservas; 3) Diretrizes Internacionais: não são vinculativas e são amplamente comentadas pelos Estados. "As diretrizes podem variar de regras fortes, explícitas e detalhadas a afirmações vagas de aspirações coletivas amorfas" (DONNELLY, 1986, p.603-604; tradução livre - Guidelines may range from strong, explicit, detailed rules to vague statements of amorphous collective aspirations); e 4) Padrões nacionais: que se caracterizam pela ausência de normas internacionais.

A partir da categorização dos tipos de regimes internacionais, realizada por Donnelly (1986), é possível situar a CEDAW dentro dessa classificação apresentada no parágrafo precedente. Como os Estados-Partes podem ratificar a Convenção com reservas ${ }^{2}$, é possível situá-la como norma internacional com exceções nacionais auto-selecionadas. Na próxima seção, o artigo apresenta o que é a CEDAW e como funciona o seu Comitê.

\footnotetext{
1 Jack Donnelly (1986, p. 617) salienta que o respeito aos Direitos Humanos dentro de um Estado ocorre como resultado da persistência de lutas políticas nacionais contra a violação desses direitos.

2 Para mais informações sobre as reservas da CEDAW, conferir UN WOMEN. Convention on the Elimination of all Forms of Discrimination against Women. Disponível em: http://www.un.org/womenwatch/daw/cedaw/reservations; Acesso em: 20/04/2017. htm A CEDAW considera inadmissível fazer reserva a alguns artigos específicos, a saber: os artigos 2, 16 e 28, parágrafo 2 .
} 


\section{CONTEXTUALIZAÇÃO SOBRE A CEDAW DENTRO DO REGIME INTERNACIONAL DE DIREITOS HUMANOS.}

Hanna Beate Schöpp-Schilling (2007) explica que os Direitos Humanos são um dos três pilares das Nações Unidas. Os outros dois seriam, respectivamente, promover e salvaguardar o desenvolvimento social e econômico e manter a segurança e a paz internacionais. A estrutura dos Direitos Humanos no âmbito internacional abrange todas as áreas da vida do indivíduo, incluindo, desse modo, direitos civis, políticos, culturais, econômicos e sociais.

Neste enquadramento dos Direitos Humanos, a CEDAW faz parte de um grupo de tratados multilaterais de Direitos humanos, podendo ser caracterizada como uma norma capaz de reconhecer a natureza particular da discriminação contra a mulher, gerando a necessidade de respostas legais (COOK, 1994, p.11). As obrigações dos Estados para com a CEDAW encontram-se presentes no artigo 2, cujo pressuposto é a condenação de todas as formas de discriminação contra as mulheres. O mesmo artigo estabelece que os EstadosPartes devem adotar, em suas Constituições nacionais, "o princípio da igualdade do homem e da mulher e assegurar por lei outros meios apropriados à realização prática desse princípio" (CEDAW, 1979).

Criada em 1979 pela Assembleia Geral das Nações Unidas, a CEDAW só entrou em vigor, de fato, em 1981, sendo o seu período de criação correspondente à década da Mulher estabelecida pela ONU (1976-1985). A Convenção também é conhecida, segundo Verdirame (2011), como o "Tratado das Mulheres" ou como a Carta Internacional de Direitos Humanos das mulheres. No dia 10 de dezembro de 1999, a CEDAW adotou o Protocolo Opcional que entrou em vigor em 22 de dezembro de 2000 , no qual se permite que

[...] as mulheres que tiveram seus direitos violados e que tenham esgotado as possibilidades de recurso às instâncias nacionais podem recorrer ao Comitê para a Eliminação de todas as Formas de Discriminação contra a Mulher, criado pela Convenção (BRASIL, 2010, p.1). 
Byrnes (2013) considera poucos casos de reclamação foram apresentados ao Comitê da CEDAW. Até o ano de 2012 foram registrados quarenta casos, sendo a maioria contra os membros do Conselho Europeu ou do Canadá. O Brasil, o Peru e as Filipinas têm um caso contra eles cada um. Segundo Schöpp-Schilling (2007), o protocolo opcional de 1999 tem dois objetivos. O primeiro é fortalecer a Convenção, por meio do "procedimento de comunicação", pelo qual grupos ou indivíduos podem relatar suas queixas ao Comitê CEDAW. O segundo objetivo é permitir, segundo Riggin (2011), que o Comitê analise potenciais abusos aos Direitos das mulheres nos países que adotaram o Protocolo através de um "procedimento de inquérito", com caráter confidencial e dependente da cooperação do Estado-membro. Este, por sua vez, pode produzir relatórios públicos para aumentar a transparência e potencializar a ação da CEDAW. Além disso, o Comitê CEDAW ampliou o tempo das reuniões por causa das intensas pressões de grupos e ONGs de Direitos Humanos das mulheres (EVATT, 2002).

Para Díaz (2014), os Direitos das mulheres são uma questão global por conta: (I) do suporte das Nações Unidas por meio da sua agenda para igualdade de gênero; (ii) do movimento das mulheres; e (iii) da opinião pública internacional e do poder democrático dos países ocidentais. Para a autora, o Protocolo Opcional adotado pela CEDAW é um importante instrumento jurídico, pois agora a Convenção possui dimensão global e pode ser utilizada por movimentos feministas pelo mundo para pressionar os Estados a reconhecer os Direitos Humanos das mulheres (DÍAZ, 2014).

Conforme informações do Alto Comissário das Nações Unidas para os Direitos Humanos (OHCHR, 2016), fazem parte, como Estados-membros da CEDAW, 177 países e 6 como signatários, sendo que 14 países não aderiram ao tratado. Por "Estados Partes" compreende-se os países que manifestaram consentimento por meio da ratificação de adesão ao tratado. "Signatários" são os países que forneceram um endosso preliminar do instrumento e sua intenção de examinar o tratado domesticamente e, eventualmente, ratificá-lo.

Composta por trinta artigos, a CEDAW entende que as discriminações contra as mulheres podem ocorrer tanto no espaço público quanto no privado, 
podendo ser diretas ou indiretas e intencionais ou não intencionais pelas leis, práticas e/ou costumes, o que lhe garante um caráter multidimensional. Como apontam Hellum e Aasen (2013), por incorporar questões públicas e privadas referentes às mulheres, a Convenção é vista de forma positiva por acadêmicas feministas construtivistas de direito, que assimilam a CEDAW "como o regime de igualdade e não-discriminação com maior potencial para assegurar uma igualdade substancial de gênero para as mulheres" (HELLUM \& AASEN, 2013, p.2; tradução livre $-[\ldots]$ as the equality and non-discrimination regime with the greatest potential to ensure substantive gender equality for women).

Com o propósito de ser uma "ferramenta sócio-jurídica" (socio-legal tool) (HELLUM, 1999 apud ALI, 2006, p.71), a CEDAW tem como objetivo garantir a igualdade e a proteção das mulheres contra toda forma de discriminação. Segundo Dairiam (2004), os principais pontos imputados aos Estados-Membros pela CEDAW são: um conjunto de valores normativos e princípios relativos à igualdade e não discriminação; um conjunto de compromissos que os Estadosmembros devem cumprir; e a obrigação de enviar relatórios periódicos ao Comitê, pelo menos, de quatro em quatro anos, sendo que eles devem incluir as áreas de progresso, bem como as áreas de dificuldades de implementação.

Schöpp-Schilling (2007, p.16) destaca cinco pontos que diferenciam a CEDAW dos demais tratados de Direitos Humanos, a saber: $\left.1^{\circ}\right)$ trata-se da primeira e única Convenção capaz de levar os Estados-membros a alterar e eliminar atitudes sociais e culturais, bem como padrões e práticas culturais baseadas na inferioridade ou superioridade de um sexo; $2^{\circ}$ ) atribui responsabilidade sobre a eliminação da discriminação contra a mulher não apenas aos agentes do Estado, mas particulares, organizações e empresas; $3^{\circ}$ ) sugere integrar o conjunto dos direitos humanos das mulheres ao quadro normativo da não discriminação e da igualdade; 4º) contempla a garantia de respeito e proteção dos Direitos Humanos das mulheres na esfera privada da família; e 5º) propõe a correção de práticas antigas de discriminação da mulher por meio da aplicação de medidas temporárias especiais.

Para tornar a Convenção mais efetiva e colocá-la em funcionamento a atuação do Comitê da CEDAW é necessária. Por meio dele, é realizado um 
trabalho de monitoramento das obrigações dos Estados signatários. O Comitê e seu papel no funcionamento do regime internacional da CEDAW serão abordados na próxima subseção deste artigo.

\subsection{O COMITÊ CEDAW}

O Comitê CEDAW (CmCEDAW) visa monitorar o progresso da implementação da Convenção nos Estados-Partes. Como explica Merry (2009), o Comitê da CEDAW é composto por vinte e três especialistas independentes que são eleitos para mandatos de quatro anos por votação secreta, realizada pelos Estados-Partes da Convenção. Os especialistas do CmCEDAW são escolhidos por região (Caribe, África, Ásia, América Latina ${ }^{3}$, Leste e Oeste Europeu) para que haja igualdade de representação. As regras de procedimento da CEDAW estabelecem "que os oficiais podem ser reeleitos, desde que o princípio de revezamento seja mantido" (UNITED NATIONS, 2011, p.7; tradução livre $-[\ldots]$ provides that officers may be re-elected, provided that the principle of rotation is upheld).

Um dos critérios utilizados na escolha dos especialistas do CmCEDAW é o alto padrão moral e competência dos candidatos, bem como sua representatividade no que se refere às diversas culturas e diferentes sistemas jurídicos. Merry (2009, p.82) examinou as biografias fornecidas à ONU pelos candidatos ao Comitê CEDAW dos anos de 2002 e 2003 e observou que $60 \%$ deles têm experiência acadêmica e/ou em ONGs. De acordo com Byrnes (2013), a maioria dos membros eleitos pelo Comitê é formada por mulheres. Até o ano de 2013, ano da pesquisa da autora, houve quatro homens eleitos. A área de experiência prévia destes especialistas são as mais diversas, entre elas, medicina, diplomacia, direito, entre outras.

\footnotetext{
3 Pelo Brasil, a jurista Silvia Pimentel foi eleita para dois mandatos no CmCEDAW (2005-2012) e atuou como presidente do Comitê nos anos de 2011 e 2012. Silvia Pimentel é doutora em Filosofia do Direito pela Pontifícia Universidade Católica de São Paulo (PUC-SP), com ênfase na área de Direitos Humanos das mulheres e militante do movimento feminista.
} 
Com o objetivo de acompanhar o progresso da implementação da Convenção CEDAW, o Comitê requer relatórios regulares dos Estados-Partes. Como explica Byrnes (2013), o objetivo do envio de relatórios alternativos pela sociedade civil e a resposta por meio de recomendações feitas pelo Comitê seriam oportunidades para os Estados-Partes

[...] avaliarem os progressos realizados na aplicação da Convenção, beneficiarem-se de um perito externo e uma avaliação objetiva da situação no país e ser responsabilizados pelos seus cidadãos por não terem garantido o exercício efetivo dos direitos garantidos na Convenção (BYRNES, 2013, p.32).

O Comitê CEDAW é o segundo Comitê de tratados de Direitos Humanos com mais relatórios analisados por ano, estando atrás apenas do Comitê para a Proteção dos Direitos de todos os Trabalhadores Migrantes e dos Membros das suas Famílias (CMW). A Organização das Nações Unidas ${ }^{4}$ ressalta que os números de relatórios analisados anualmente podem variar caso o Comitê utilize mais horas de reunião ${ }^{5}$. Em geral, os Estados apresentam relatórios e dialogam com o Comitê, segundo Merry (2009, p.81), mesmo aqueles que apresentam reservas significativas à Convenção.

Para a elaboração das observações finais ou recomendações gerais, 0 CmCEDAW se reúne em sessão fechada a fim de expressar suas preocupações sobre esforços que precisam ser realizados pelos Estados-membros para se adequarem às normas da CEDAW. Feitas as observações finais, o Comitê identifica quais são as recomendações prioritárias e solicita aos Estados-Partes

\footnotetext{
${ }^{4}$ Conferir UNITED NATIONS, 2011.

${ }^{5}$ No começo das revisões dos relatórios dos Estados-Partes, o Comitê CEDAW se reunia todo o ano por duas semanas. Porém, esse tempo foi estendido e o CmCEDAW reúne-se, atualmente, por três semanas mais o tempo adicional para a reunião dos grupos de trabalho anteriores a cada sessão. Assim que o Estado-parte apresenta seu relatório, há uma sessão pública, realizada na sala de conferências do edifício da ONU em Nova York, na qual a delegação enviada pelo Estado-parte faz uma introdução de, no máximo, 30 minutos. Na sequência, o CmCEDAW elabora uma lista de até trinta questões sobre "as discrepâncias entre as ações do país e as obrigações que assumiu ao ratificar a convenção" (MERRY, 2009, p. 82) e envia-o ao Estadoparte. O envio é realizado "geralmente duas sessões antes da sessão na qual o relatório está programado para ser considerado, com um pedido para que o Estado-parte responda dentro de seis semanas" (BYRNES, 2013, p. 34). As respostas devem ser "curtas, precisas e diretas e com menos de 25 a 30 páginas" (UNITED NATIONS, 2011, p.14). Sendo que é vetada a participação de membros do CmCEDAW originários do país cujo relatório está sendo considerado.
} 
a apresentação de um relatório no prazo de um a dois anos. Nesse relatório, devem constar as medidas adotadas pelo país para seguir as recomendações do CmCEDAW (BYRNES, 2013, p.37).

Quanto às recomendações, como apontado por Schöpp-Schilling (2007), ao longo do tempo novas temáticas são anexadas, sendo específicas a cada país. Por exemplo, do relatório inicial brasileiro de 2003 em comparação com último (de 2012), as temáticas de casamento e relacionamentos familiares, mulheres em detenção, Declaração de Beijing e Plataforma de Ação, Desenvolvimento dos Objetivos do Milênio e grupos desfavorecidos de mulheres foram acrescentadas. Schöpp-Schilling denomina a introdução dessas novas temáticas de medidas corretivas ou Temporary special issues.

Este diálogo e interação entre os Estados-Partes são chamados, pelas Nações Unidas e pelo Comitê CEDAW, de "diálogo construtivo". Para obter informações específicas de cada país, o CmCEDAW e os seus grupos de trabalho convidam organizações da sociedade civil que podem participar regularmente das reuniões do Comitê. Além disso, Shin (2004) acredita que a participação de ONGs de mulheres no Comitê e nas reuniões gera um aumento da responsabilidade dos Estados-Partes e maior transparência no processo de elaboração de relatórios, assim como na implementação das recomendações no âmbito doméstico.

De acordo com Merry (2009), o Comitê CEDAW é muito mais receptivo aos inputs (demandas) de ONGs do que de órgãos de base da ONU como, por exemplo, a Comissão sobre a Situação da Mulher ou o Alto Comissariado de Direitos Humanos. Segundo a autora, "muitos dos membros do Comitê CEDAW são bastante positivos sobre as ONGs e fazem um esforço para ouvi-los informalmente" (MERRY, 2009, p.87; tradução livre - [...] many of the members of the CEDAW Committee are quite positive toward NGOs and make an effort to listen to them informally), especialmente aqueles especialistas que passaram por ONGs anteriormente.

A participação de atores não-estatais feministas no Comitê CEDAW ocorre desde 1988, porém de maneira informal. Segundo Shanthi Dairiam 
(2007), foi somente no ano de 1997 que se legitimou a participação de atores não-estatais feministas no Comitê CEDAW. Como descreve a autora, a IWRAW Asia Pacific (International Women's Rights Action Watch) iniciou, em 1997, um programa chamado "Do global ao Local", que contava com o apoio da Fundação Ford, do UNIFEM (Fundo de Desenvolvimento das Nações Unidas para a Mulher) e do Fundo de População das Nações Unidas (UNFPA). A criação desse programa visava capacitar as ativistas não-estatais feministas dos EstadosPartes, a fim de facilitar a participação delas nas reuniões do Comitê CEDAW. Com isso, elas poderiam observar o funcionamento e a postura dos seus Estados. Dessa forma, elas poderiam: (I) apresentar informações alternativas ausentes nos relatórios dos Estados; (ii) levantar questões para o debate dentro do Comitê; e (iii) estabelecer planos para monitorar se os países estariam cumprindo as recomendações contidas nas observações finais do Comitê. (DAIRIAM, 2007, p.315).

Os dados acima mostram que as ações de ONGs e outras organizações de mulheres tornaram-se fundamentais para o trabalho do Comitê, pois elas fornecem informações fundamentais sobre a situação das mulheres no nível doméstico. Muitas vezes, os relatórios dos Estados apresentavam lacunas no fornecimento dessas informações. Segundo Shin (2004), a participação de ONGs de mulheres no Comitê e nas reuniões ( $I$ ) aumenta a responsabilidade dos Estados-Partes, (ii) favorece a transparência no processo de elaboração de relatórios e (iii) possibilita a implementação, no âmbito doméstico, da Convenção.

No caso brasileiro, a interação entre o Comitê CEDAW e os atores nãoestatais feministas brasileiros apresenta ganhos relevantes, pois tais atores encaminham relatórios alternativos ao Comitê por meio dos quais compilam casos, dados e reflexões dos movimentos de mulheres brasileiras, com pesquisas elaboradas na universidade e pela sociedade civil. Desse modo, o relatório alternativo dá outra interpretação aos mesmos dados que o governo apresenta. Este relatório alternativo pode, dessa forma, apresentar as 
inconsistências ou lacunas existentes nos relatórios oficiais enviados pelo Estado brasileiro.

Outra área de atuação da sociedade civil organizada é no desenvolvimento de profissionais com competências específicas para lidar com a implementação de tratados internacionais no Brasil. Para Silvia Pimentel (2007), o treinamento de profissionais conhecedores do Direito Internacional de Direitos Humanos é imprescindível ao Brasil, tendo em vista a sua dimensão continental e à sua diversidade regional. No período de 1999 a 2000, a CLADEM (Comitê Latino-Americano e do Caribe para a Defesa dos Direitos da Mulher) e o Instituto para Promoção da Equidade treinaram mil profissionais brasileiros em Direito Internacional de Direitos Humanos, com o objetivo de alertá-los sobre "os estereótipos, preconceitos e formas de discriminação ainda presentes na arena jurídica" (PIMENTEL, 2007, p.100; tradução livre - [...] the stereotypes, prejudices, and forms of discrimination still present in the legal arena). Os focos principais do treinamento eram as questões de gênero, raça/etnia, desigualdade econômica e a discriminação e violência contra as mulheres. Na avaliação dos participantes o impacto foi extremamente positivo.

$\mathrm{Na}$ próxima seção, o artigo apresentará e discutirá as principais recomendações do Comitê CEDAW ao Estado brasileiro.

\section{AS PRINCIPAIS RECOMENDAÇÕES DO COMITÊ CEDAW AO ESTADO BRASILEIRO}

Segundo a Secretaria Especial de Políticas para as Mulheres (BRASIL, 2010), o Estado brasileiro ratificou a CEDAW em 1984, tendo formulado reservas aos artigos 15, parágrafo $4^{06}$, artigo 16, parágrafo 1丷, as linhas (a), (c), (g) e (h) e artigo 29. No ano de 1994, as reservas aos artigos 15 e 16 foram retiradas. Essas reservas diziam respeito à incompatibilidade da legislação brasileira com os princípios de igualdade da Convenção. A reserva ao artigo 29 ainda continua,

\footnotetext{
${ }^{6}$ Artigo 15 - 4응 Os Estados-Partes concederão ao homem e à mulher os mesmos direitos no que respeita à legislação relativa ao direito das pessoas à liberdade de movimento e à liberdade de escolha de residência e domicílio.
} 
pois se refere à interpretação de cada Estado-Parte sobre a Convenção e sua implementação. No ano de 2002, o Estado brasileiro aderiu ao Protocolo Opcional da CEDAW e enviou o primeiro relatório ao Comitê.

As recomendações do Comitê CEDAW serão analisadas, nesta seção do artigo, com base nas respostas desse Comitê a três relatórios enviados pelo Estado brasileiro. O primeiro deles, de 2002, corresponde aos anos de 1985, 1989, 1993, 1997 e 2001. O segundo relatório corresponde aos anos de 2001 a 2005 e o terceiro abrange o período de 2006 a 2009.

Sobre o primeiro relatório, o Comitê destaca o alto nível da representação brasileira, presidida pela Secretaria Especial de Políticas para as Mulheres, uma pasta com nível ministerial. Dentre os temas abordados nas observações finais do Comitê CEDAW ao Estado brasileiro, é possível observar o predomínio de quatro deles, a saber: $1^{\circ}$ Tráfico e exploração da prostituição; $2^{\circ}$ Educação; $3^{\circ}$ Emprego/trabalho e Violência contra as mulheres; 4- Acesso das mulheres a cargos políticos. Os mesmos temas aparecem com maior evidência nas recomendações enviadas ao segundo relatório brasileiro. As recomendações de ambos serão detalhadas na sequência.

No que se refere ao tráfico e exploração da prostituição, o Comitê preocupa-se com a falta de informações sobre a extensão do fenômeno e com a ausência de uma abordagem global e concertada para combater o tráfico de pessoas no Brasil. O CmCEDAW lamenta que o país não adotou, ainda, uma legislação global de luta contra o tráfico. Desse modo, o Comitê recomenda que o país considere adotar uma lei abrangente contra o tráfico de pessoas, em linha com o Protocolo de Palermo ${ }^{7}$, a fim de implementar plenamente o artigo $6^{0}$ da Convenção e assegurar que os perpetradores sejam processados e punidos e as vítimas adequadamente protegidas e assistidas. O Comitê CEDAW recomenda que o Estado brasileiro aplique eficazmente suas medidas contra 0

\footnotetext{
7 Instrumento legal internacional que trata do tráfico de pessoas, em especial de mulheres e crianças, o Protocolo de Palermo foi elaborado em 2000, tendo entrado em vigor em 2003 e ratificado pelo Brasil por meio do Decreto oㅡ 5.017, de 12/03/2004. Ele é oficialmente conhecido como "Protocolo Adicional à Convenção das Nações Unidas contra o Crime Organizado Transnacional Relativo à Prevenção, Repressão e Punição do Tráfico de Pessoas, em Especial Mulheres e Crianças".
} 
tráfico, o que envolve implementar a Política Nacional de Combate ao Tráfico de Pessoas. O Comitê solicitou, ainda, a adoção, pelo Brasil, de medidas cujo objetivo seria reduzir a vulnerabilidade das mulheres e meninas aos traficantes.

Sobre a temática de Violência contra a mulher, o Comitê recomenda que - Estado brasileiro forneça treinamento sistemático para juízes, promotores e advogados sobre direitos e violência contra as mulheres, bem como sobre a Lei Maria da Penha e sua constitucionalidade. Além disso, o Comitê solicita o fortalecimento do sistema judicial brasileiro para garantir o acesso efetivo das mulheres e dos grupos desfavorecidos à justiça. Para isso, recomenda o aumento do número de tribunais para lidar com casos de violência doméstica e familiar, utilizando juízes com mais experiência nesses casos. O Comitê recomenda, também, o incremento do sistema de coleta e análise regular de dados estatísticos destinados a avaliar e acompanhar o impacto da Lei Maria da Penha.

Sobre a temática de Educação, o Comitê CEDAW recomenda a adoção, pelo Brasil, de medidas destinadas à superação das desigualdades no acesso à educação para meninas e mulheres, devido à sua raça, à sua etnia e à sua origem socioeconômica. Além disso, recomenda melhorar a taxa de alfabetização de mulheres com mais de 15 anos e estabelecer meios para induzir uma mudança cultural importante relativa à escolha da formação profissional. $O$ Comitê sugere combater práticas que induzem as meninas a não buscar áreas não tradicionais de estudos para as mulheres, como as tecnológicas.

Sobre a temática de Emprego/Trabalho, o Comitê sugere que o Estado brasileiro priorize a adoção do projeto de lei sobre a igualdade no local de trabalho (n.. 6653/2009), que prevê a criação de mecanismos para prevenir e proibir a discriminação contra as mulheres no trabalho. O Comitê observa a existência de segregação profissional baseada em estereótipos de gênero, de raça e de etnia, além de problemas relacionados às diferenças salariais entre homens e mulheres. Recomenda, ainda, que o Estado brasileiro promova a adoção de medidas legislativas para ( $($ ) proteger as mulheres contra o assédio sexual no local de trabalho e (ii) realizar os direitos das mulheres no setor informal. Por fim, o Comitê revela preocupação com a situação das 
mulheres trabalhadoras domésticas, sobretudo as de ascendência africana, que se encontram excluídas da proteção dos direitos trabalhistas e são vulneráveis à exploração e ao abuso sexual.

Com base nas informações do terceiro relatório, o Comitê CEDAW elaborou vinte questões ao Brasil na $51^{\underline{a}}$ sessão (realizada em 2012). Dividida por temáticas, o documento abrange 12 delas, a saber: Geral; Quadro constitucional e legislativo; Mecanismo nacional de gênero; Medidas temporárias especiais; Violência contra as mulheres; Tráfico e exploração de prostituição; Participação política e processo decisório; Educação; Trabalho/Emprego; Saúde; Grupos de mulheres desfavorecidas e Casamento e relações familiares.

$\mathrm{Na}$ lista de questões da $51^{\text {a }}$ sessão do Comitê CEDAW é possível identificar, também, o predomínio de alguns temas que tiveram maior atenção. Desses temas, dois receberam maior número de indagações: os mecanismos nacionais de gênero e a saúde.

Com o maior número de indagações, a temática sobre os Mecanismos nacionais de gênero envolveu o interesse do CmCEDAW em saber sobre a Secretaria Especial de Políticas para as Mulheres (SPM) e esclarecer que tipo de coordenação existe entre os mecanismos de gênero em diferentes níveis da federação brasileira e se existe uma entidade com plena capacidade e autoridade para coordenar suas ações. O Comitê solicitou, também, mais informações sobre os resultados do Primeiro Plano Nacional de Políticas para as Mulheres (I PNPM) de 20048. Esses resultados foram analisados durante a Segunda Conferência Nacional sobre a Mulher em Agosto de 2007. E pediu, também, esclarecimentos sobre a estrutura criada para coordenar a implementação do Pacto Nacional de Combate à Violência contra as Mulheres nos níveis federal, estadual e municipal. E requisitou, por fim, mais informações sobre o mandato das mulheres no Congresso Nacional e os resultados obtidos no que se refere ao avanço dos direitos da mulher no Brasil.

\footnotetext{
8 O I Plano Nacional de Políticas para as Mulheres foi criado em 2004 enquanto o II Plano foi aprovado em 2008. O segundo Plano é, em parte, resposta às recomendações do Comitê CEDAW, conforme será possível notar na próxima subseção deste artigo, quando for tratada a questão da saúde.
} 
No que se refere à temática da saúde, o Comitê solicitou que o Estado brasileiro fornecesse informações sobre as medidas específicas adotadas para enfrentar a questão dos abortos inseguros e a discriminação contra as mulheres e adolescentes que se dirigem aos centros de saúde com abortos ou são vítimas de violência por causa de padrões culturais conservadores. O Comitê solicitou, também: (I) informações sobre as medidas específicas destinadas a combater 0 crescimento persistente da infecção por HIV/AIDS feminina, especialmente entre adolescentes e mulheres adultas casadas; e (ii) informações sobre as medidas previstas para lidar com casos de esterilização forçada de mulheres, sobretudo entre pobres e de ascendência africana.

Na sequência, as recomendações do Comitê serão analisadas à luz dos dados oficiais sobre a situação dos direitos humanos das mulheres. A análise concentrou-se nos principais temas apresentados nas recomendações endereçadas ao Estado brasileiro.

\subsection{DISCUSSÃO DOS RESULTADOS}

Os três relatórios do Comitê CEDAW apresentam, com maior evidência, três temas principais. $O$ primeiro deles refere-se ao tráfico humano e à violência contra a mulher. $\mathrm{O}$ segundo envolve $\mathrm{o}$ acesso das mulheres a direitos sociais básicos, como saúde e educação. $\mathrm{E}$ o terceiro corresponde às condições de trabalho e de acesso às oportunidades políticas e econômicas. Sobre esse terceiro tema, é interessante observar a preocupação do Comitê com o acesso das mulheres brasileiras aos cargos públicos e como ele destacou a vitória da presidente Dilma Rousseff em 2010, como a primeira mulher a ocupar a presidência da República no Brasil. No entanto, mudanças nas condições de trabalho e de acesso aos cargos públicos dependem, ainda, de alterações culturais mais profundas que não podem ser encaminhadas apenas com a adoção de políticas públicas. Nas recomendações enviadas pelo Comitê, é possível destacar, em diversos momentos, a necessidade de adoção de programas de conscientização, capazes de enfrentar práticas de discriminação contra as mulheres no Brasil, seja no ambiente de trabalho, seja ao longo do processo educacional. A existência de discriminação contra mulheres que optam 
por profissões tradicionalmente atribuídas aos homens, sobretudo nas áreas tecnológicas, indica a necessidade de mudanças culturais que podem surgir com o tempo.

No Brasil, apesar dos avanços observados na legislação e nas políticas de combate à violência contra a mulher no período de 2003 a 2014, os dados são preocupantes, ainda, e revelam, talvez, uma das maiores dificuldades de compliance do Estado brasileiro em relação à Convenção. A principal mudança legislativa foi a criação da Lei Maria da Penha, sancionada em 2006 (Lei no 11.340). O caso Maria da Penha, como expresso por Pimentel e Piovesan (2011), permitiu retirar o véu da invisibilidade sobre a questão da violência doméstica no Brasil e contribuiu para o combate à impunidade dos agressores por parte do Estado brasileiro.

De modo breve, como descrito por Pimentel e Piovesan (2011), a criação da Lei foi resultado em parte da condenação do Brasil pela Comissão Interamericana, em 2011. A Comissão condenou o país por negligência e omissão em relação à violência doméstica e redigiu algumas recomendações ao Estado brasileiro. Essas recomendações diziam respeito aos deveres assumidos pelo Estado em relação à ratificação da Convenção Americana de Direitos Humanos e da Convenção Interamericana para Prevenir, Punir e Erradicar a Violência contra a Mulher (Convenção de Belém do Pará). Dentre as recomendações, é possível destacar, como exemplos, campanhas de prevenção e programas de capacitação e sensibilização dos agentes da justiça. Elas fizeram parte de um termo de compromisso firmado entre entidades peticionárias e o Estado Brasileiro (PIMENTEL e PIOVESAN, 2011, p.111-112). Em 2002, o réu do caso Maria da Penha foi, finalmente, preso na Paraíba. No ano de 2003, foi adotada a Lei 10.778, segundo a qual vítimas de violência contra a mulher deveriam ser atendidas pelos serviços públicos ou privados de saúde. Em 2004, foi criado

[...] um grupo de trabalho Interministerial, que contou com a participação da sociedade civil e do Governo, para elaborar proposta de medida legislativa e outros instrumentos para coibir a violência doméstica contra a mulher (PIMENTEL e PIOVESAN, 2011, p.112). 
Em 2006, finalmente, foi criada a Lei Maria da Penha, que estabeleceu: (I) mecanismos para diminuir a violência doméstica e familiar contra a mulher; e (ii) medidas para prevenção, assistência e proteção às mulheres em situação de violência (PIMENTEL e PIOVESAN, 2011, p.112). Como expresso por Pimentel e Piovesan (2011), a lei Maria da Penha foi o resultado exitoso de uma articulação do movimento de mulheres brasileiras, ao identificarem um caso emblemático de violência contra a mulher e submetê-lo à arena internacional, por meio de um ativismo transnacional e da luta "pela efetiva implementação da lei" (PIMENTEL e PIOVESAN, 2011, p.115).

É possível notar que, apesar de seus impactos positivos no combate à violência contra as mulheres, a lei não alterou, de modo expressivo, o número de mortes resultantes dessa violência. De acordo com Waiselfisz (2015), , os dados do Mapa da Violência mostram que, entre os anos de 2003 e 2013, o número de vítimas do sexo feminino passou de 3.937 para 4.762, um aumento de $21 \%$ na taxa de mulheres mortas no período. Como aponta a pesquisa, 0 número de 4.762 mortes ocorridas no ano de 2013 corresponde a 13 homicídios femininos diários, sendo a maioria formada por mulheres negras.

De acordo com estatísticas internacionais disponibilizadas no Mapa da Violência do Brasil (2015), o país só está atrás de El Salvador, da Colômbia, da Guatemala e da Rússia quanto às taxas de feminicídio. Além disso, o Brasil apresenta 48 vezes mais homicídios femininos que o Reino Unido, 24 vezes mais que Irlanda ou Dinamarca e 16 vezes mais que Japão ou Escócia. Os índices mundiais de feminicídio apontam para a periculosidade do sexismo, responsável pela morte diária de mulheres. Como aponta Bunch (1990), quando o sexismo é "combinado com a raça, classe e outras formas de opressão, se constitui uma negação mortal do direito das mulheres à vida e à liberdade em grande escala em todo o mundo" (BUNCH, 1990, p.489; tradução livre - [...] when combined with race, class and other forms of oppression, it constitutes a deadly denial of women's right to life and liberty on a large scale throughout the world). Desse modo, os índices podem se tornar ainda mais alarmantes ao passo que muitas mulheres no Brasil não denunciam a agressão por diversos motivos, entre os 
quais o medo e a falta de reconhecimento da capacidade do Estado de acolher suas demandas de forma adequada e oferecer proteção efetiva.

Além das mortes provocadas pela violência doméstica e sexual, outro dado a ser destacado refere-se à mortalidade materna. Esse tema situa-se nas recomendações do Comitê CEDAW no que se refere ao acesso aos direitos sociais básicos de saúde. No Brasil, esta mortalidade vem apresentando redução ao longo dos anos, tendo alcançado, em 2005, o valor corrigido de 74,6 óbitos maternos por 100 mil nascidos vivos (como expresso no II Plano Nacional de Política para mulheres, de 2008, BRASIL (2008)). Mesmo que em patamares ainda bastante elevados, a mortalidade materna apresentou redução por causa da melhoria na qualidade obstétrica e no planejamento familiar. Essa melhoria é resultante de políticas públicas adotadas a partir de 2003 e destinadas à redução da mortalidade materna. É o caso, por exemplo, do Pacto Nacional pela Redução da Mortalidade Materna e da Política Nacional de Atenção Integral à Saúde da Mulher, ambos de 2004. Essa política foi baseada na integralidade e na promoção à saúde como princípios norteadores e visava garantir condições para: (I) a melhoria da atenção obstétrica; (ii) o planejamento familiar; e (iii) 0 combate à violência doméstica e sexual. Além disso, essa política buscava prevenção e tratamento de mulheres com HIV/AIDS - uma das preocupações do Comitê CEDAW, expressa nas suas recomendações ao Brasil. O II Plano Nacional de Políticas para as Mulheres apresenta-se, inclusive, como resposta às recomendações do Comitê:

As ações dispostas neste II PNPM vão ao encontro das recomendações propostas pelo Comitê Cedaw, tendo por objetivos centrais aprofundar os processos de mudanças de paradigmas na atenção obstétrica e no controle do câncer de colo de útero e de mama; efetivar as políticas lançadas na gestão anterior (Pacto Nacional pela Redução da Mortalidade Materna, Política Nacional de Planejamento Familiar, Plano de Enfrentamento da Feminização da Aids e Pacto Nacional de Enfrentamento da Violência contra Mulheres); iniciar e/ou consolidar a organização da atenção às ações de saúde introduzidas nos quatro anos anteriores, buscando a integralidade (climatério, queixas ginecológicas, saúde mental e gênero, reprodução humana assistida, mulheres em situação de prisão, mulheres negras, indígenas, mulher na terceira idade, lésbicas e bissexuais); e incorporar novos segmentos populacionais às políticas como forma de 
assegurar os princípios da integralidade, equidade e universalidade preconizados no Sistema Único de Saúde. (BRASIL, 2008, p.79).

Apesar dos avanços das políticas públicas de saúde desde 2003, os dados são preocupantes e revelam os limites dessas políticas. Em 2012, foram registradas 63,9 mortes por 100 mil nascidos/vivos, segundo dados do Relatório Anual Socioeconômico da Mulher, de 2014 (BRASIL, 2015). Ressalta-se que a assistência ao parto não é homogênea em todo o Brasil. Para as mulheres da área rural, o parto domiciliar assistido por parteiras tradicionais é uma realidade recorrente. As regiões Norte, Nordeste e Centro-Oeste apresentavam, em 2012, percentuais significativos de mortes de gestantes, acima da média nacional (72,1\%,70,3\% e $67,2 \%$, respectivamente). Outro dado preocupante refere-se às desigualdades quanto à raça das gestantes falecidas. No Brasil, a mortalidade de gestantes negras correspondia, em 2012, a 62,8\% do total de mulheres mortas durante a gravidez e o puerpério, enquanto o percentual entre as mulheres brancas era equivalente a 34\% (BRASIL, 2015, p.30). O Relatório Anual Socioeconômico das Mulheres, de 2014, ressalta que há margem para a redução da mortalidade materna, tendo em vista "que as causas obstétricas diretas, relacionadas à gravidez e em grande medida evitáveis, são as mais frequentes: foram 42,4 mortes por 100.000 nascidas/os vivas/os em 2011" (BRASIL, 2015, p.29; grifo nosso). Em 2012, segundo o mesmo Relatório, essas causas foram responsáveis por $66 \%$ da mortalidade materna no Brasil enquanto a hipertensão provocou $20,6 \%$ das mortes das gestantes (idem). As duas causas revelam o limite das políticas públicas da área de saúde, adotadas durante os últimos governos, e a necessidade de novos avanços nessa área.

Quanto à questão da educação, estatísticas de gênero apontam que a escolaridade das mulheres aumentou em relação à dos homens. Os dados pertencem à pesquisa realizada pelo IBGE (Instituto Brasileiro de Geografia e Estatística) - intitulada Estatísticas de Gênero: Uma análise dos resultados do Censo Demográfico 2010 (IBGE, 2014) . Eles mostram que houve, em 2010, um

\footnotetext{
${ }^{9}$ A pesquisa foi realizada em parceria com a Secretaria Especial de Políticas para as Mulheres (SPM) e com o Ministério do Desenvolvimento Agrário (MDA).
} 
aumento de $9,8 \%$ da frequência escolar feminina no ensino médio quando comparado ao percentual observado no Censo de 2000. Constatou-se, também, um crescimento do contingente de mulheres entre os universitários de 18 a 24 anos no ensino superior em 2010. Os dados de 2010 mostram que as mulheres representavam um total de $57,1 \%$ do total de estudantes nesse nível de ensino. Para os autores da pesquisa do IBGE, outro fator importante para o aumento da escolaridade das mulheres foi a redução na proporção de adolescentes (entre 15 e 19 anos) com filhos. A gravidez precoce é apontada, na pesquisa, como um dos motivos pelos quais adolescentes interrompem os estudos e comprometem sua formação profissional.

O II Plano Nacional de Políticas para as Mulheres foi criado em 2008 e revisado em 2013, no primeiro governo Dilma Rousseff (2011-2014), pela Secretaria Especial de Políticas para as Mulheres (SPM). Nessa revisão do II Plano (2013-2015) (BRASIL, 2013), a SPM trata a educação como um dos eixos fundamentais para a construção de uma sociedade igualitária entre mulheres e homens. A Secretaria reconhece avanços nas taxas de matrícula nos níveis de ensino e no acesso das mulheres às oportunidades educacionais. No entanto, destaca "a persistência de graves desigualdades associadas à discriminação sexista, étnica e racial, à concentração de renda, à distribuição desigual de riqueza entre campo e cidade" (BRASIL, 2013, p.22). Nesse sentido, o Brasil não se mostrou capaz, ainda, de minimizar essas desigualdades, conforme recomenda o Comitê CEDAW, por meio de medidas destinadas à superação das disparidades no acesso à educação para meninas e mulheres, devido à sua raça, à sua etnia e à sua origem socioeconômica. "A taxa de analfabetismo das mulheres negras é o dobro da taxa das mulheres brancas e o acesso à educação das meninas e mulheres das áreas rurais é menor, em relação às que vivem nas áreas urbanas" (BRASIL, 2013, p.23). Para enfrentar a discriminação contra as mulheres, a Secretaria sugere mudanças na política educacional para consolidar "as perspectivas de gênero, raça, etnia, orientação sexual, geracional" (idem) e considera a escola como espaço importante na medida em que ela pode reproduzir desigualdades observadas na sociedade por meio dos seus 
currículos, dos seus livros didáticos e das suas práticas desenvolvidas no ambiente das salas de aula.

No que diz respeito às oportunidades econômicas e políticas das mulheres, os dados mostram que o Brasil precisa buscar avanços nessa temática. Dados do Relatório Anual Socioeconômico da Mulher revelam que persistem, no mercado de trabalho, desigualdades geradas pelo sexo (BRASIL, 2015), que se somam às disparidades regionais e por grupos de idade. $O$ Relatório mostra, também, que as desigualdades de raça persistem. Em 2012, a taxa de atividade das mulheres entre 16 e 59 anos era de $64,2 \%$ contra $86,2 \%$ dos homens. A taxa de atividade das mulheres negras, por sua vez, correspondia a $62,2 \%$, pouco abaixo do percentual das mulheres em geral (64,2\%). O mesmo Relatório destacou, também, a sobrecarga de trabalho das mulheres que acumulam as funções domésticas e revelou que 0 trabalho doméstico remunerado continua sendo uma das principais ocupações das mulheres - 92\% do total de trabalhadores domésticos é formado por mulheres. Desse total, $63,4 \%$ é de mulheres negras (BRASIL, 2015). Mudanças jurídicas precisam ser destacadas como positivas no que se refere ao trabalho doméstico remunerado. É o caso, por exemplo, da Emenda Constitucional no 72/2013, que estendeu, aos trabalhadores domésticos, direitos concedidos pela Constituição aos demais trabalhadores.

A participação política das mulheres é outro tema das recomendações do Comitê CEDAW. Ela envolve a atuação em diversas atividades:

[...] desde organizações da sociedade, passando pelos partidos políticos, até a ocupação de cargos e de mandatos eletivos no Estado, especialmente nos poderes legislativo e executivo e nas instâncias federal, estadual, distrital e municipal (BRASIL, 2008, p.115).

Como avanços, o Relatório Anual Socioeconômico da Mulher (BRASIL, 2015, p.44) destaca a Lei no 12.034/2010, que obrigou os partidos políticos a destinarem, pelo menos, $30 \%$ das vagas às candidatas mulheres. Essa Lei estabeleceu, também, que $5 \%$ das receitas dos partidos, oriundas do Fundo Partidário, seja destinado "à participação política das mulheres e instituiu um tempo mínimo de difusão em rádio e televisão para incentivar a igualdade de gênero e a participação das mulheres na política" (BRASIL, 2015, p.44). Os 
números, no entanto, não são positivos, pois mostram que apenas 44 das 513 cadeiras da Câmara dos Deputados são ocupadas por mulheres, ou 8,6\% do total (SPOHR et. al., 2016, p.432). Alexandre Spohr et. al. (2016, p.432) mostram que a existência das cotas não é suficiente para gerar maior participação das mulheres no parlamento brasileiro:

Com a análise da legislação, pode-se perceber que a combinação da lista aberta e o sistema de cotas específico do Brasil (sem sanções ou obrigação de registrar o número máximo de candidatos) não propiciam a participação de mulheres [...] (SPOHR et. al., 2016, p.432).

Mesmo com a Lei no 12.034/2010, não há mudanças substanciais nesse quadro. Luis Felipe Miguel (2000) já revelava ceticismo com relação às cotas em um artigo publicado antes da lei 12.034 de 2010. Para ele, "a valorização da participação política das mulheres não depende da eleição de mais parlamentares do sexo feminino" (MIGUEL, 2000, p.100), embora a presença obrigatória de mais candidatos possa servir como estímulo à formação de lideranças políticas femininas (idem). Mas os resultados eleitorais posteriores a lei de 2010 mostram que a existência de cotas não é suficiente para aumentar o engajamento político das mulheres na vida parlamentar brasileira. A participação política das mulheres também é menor, quando se considera o número de cargos de liderança dos partidos políticos com representação feminina no Congresso Nacional. Segundo o Relatório Anual Socioeconômico da Mulher (BRASIL, 2015, p.46), "elas representavam, aproximadamente, $18 \%$ do quadro das executivas nacionais". O Relatório destaca, no entanto, que existe um interesse maior das mulheres pelo direito de participar das decisões dos partidos políticos, expresso na "existência de instâncias de mulheres na quase totalidade dos partidos políticos com representação no Congresso (91,3\%)" (BRASIL, 2015, p.46).

A participação das mulheres não é substantiva, também, no que se refere aos cargos dos mais altos níveis de gestão dos órgãos governamentais. Segundo o Relatório Anual Socioeconômico da Mulher (BRASIL, 2015, p.44), as mulheres em cargos de Direção e Assessoramento Superiores (DAS) 
correspondiam a $39 \%$ do total em fevereiro de 2014 , em média, contra $61 \%$ dos homens.

Esse conjunto de dados sobre a violência contra a mulher e sobre o acesso aos direitos sociais básicos de educação e saúde e às oportunidades econômicas e políticas revela avanços pontuais, mas persistem problemas sociais e culturais que impactam, ainda, a compliance do Estado brasileiro no que se refere ao conteúdo da CEDAW. Como ressalta Schöpp-Schilling (2007), para se ratificar um tratado sobre discriminação contra as mulheres é necessário um longo processo que envolve vontade política, visto que a ratificação de uma Convenção como a CEDAW implica desafiar padrões tradicionais préestabelecidos que subordinam as mulheres. Outro impasse pode estar na complexidade da estrutura política federal dos Estados-membros. Essa complexidade pode dificultar uma implementação consistente da Convenção.

É preciso ressaltar que houve, desde 2003 no Brasil, mudanças no que se refere ao desenvolvimento de políticas públicas destinadas ao combate à discriminação contra as mulheres e à realização dos seus direitos sociais básicos, como saúde e educação. Essas mudanças podem ser observadas, por exemplo, na criação e na consolidação institucional da Secretaria de Políticas para as Mulheres em 2003. Simone R. Bohn (2010) destaca o avanço promovido no governo Lula (2003-2010) no que se refere ao fortalecimento institucional e orçamentário dessa Secretaria. A autora considera que ela não foi a primeira agência da burocracia federal dedicada à igualdade de gênero (BOHN, 2010, p.85). Antes dela, o Conselho Nacional de Defesa dos Direitos da Mulher era encarregado dos direitos das mulheres. Mas a SPM consolidou-se institucionalmente ao longo do governo Lula por estar vinculada ao Gabinete da Presidência da República, tendo status de ministério dentro da administração federal. Além disso, recebeu, durante esse governo, aportes de recursos destinados ao desenvolvimento das ações e projetos por ela promovidos e estabeleceu laços intensos com o movimento de mulheres, gerando uma cooperação relevante entre as partes - governo federal e sociedade civil (BOHN, 2010). 
Assim, apesar das contribuições do Comitê e dos avanços promovidos nos últimos anos (sobretudo no período de 2003 a 2014), o Brasil não apresentou mudanças expressivas no que se refere aos aspectos culturais e ao combate a todas as formas de discriminação contra as mulheres. Confirma-se a abordagem de Oran Young (1989), apresentada na primeira seção deste artigo, segundo a qual regimes de Direitos Humanos dependem de uma mudança cultural e não apenas jurídica no interior dos Estados, produzindo, por consequência, reflexos no funcionamento desses regimes. Nesse sentido, a compliance do Estado brasileiro à CEDAW depende não apenas da continuidade das políticas públicas - afetada pela crise fiscal, pela mudança recente de governo após o impeachment da presidente Dilma Rousseff e pela reorientação das prioridades de aplicação dos recursos públicos, que afetam áreas como saúde, educação e previdência social. A compliance depende, também, de uma mudança maior no conjunto de valores e práticas que orienta a ação dos agentes públicos e privados envolvidos na realização dos Direitos Humanos das mulheres. Isso explicaria as dificuldades dessa Convenção para se tornar mais efetiva no Brasil.

\section{CONSIDERAÇÕES FINAIS}

No período pós-redemocratização, o Brasil assumiu compromissos internacionais de Direitos Humanos, ampliando e reforçando o universo dos Direitos fundamentais garantidos pelo Estado. Em 2003, foram criadas a Secretaria Especial de Políticas para Mulheres, a Secretaria Especial para a Promoção dos Direitos Humanos e a Secretaria Especial de Políticas para a Promoção da Igualdade Racial. Para Miranda (2014), a criação da Secretaria Especial de Políticas para Mulheres expressa o reconhecimento, por parte do governo brasileiro, da "necessidade de produção de políticas públicas específicas, coordenando e incentivando ações nos órgãos governamentais, com vistas à transversalidade de gênero" (MIRANDA, 2014, p.12).

A criação dessas Secretarias e o desenvolvimento de avanços na legislação e nas políticas públicas produzem resultados menos expressivos 
quando confrontados com as práticas existentes na sociedade brasileira e com os dados sobre: a violência contra a mulher; as oportunidades econômicas e políticas a elas disponíveis; e o acesso aos direitos sociais básicos, como saúde e educação. O Brasil continua oscilando entre avanços em termos legais e institucionais e retrocessos práticos resultantes da lentidão das mudanças culturais que seriam capazes de limitar as diversas formas de discriminação contra a mulher. Ao mesmo tempo, o país apresenta dificuldades para produzir políticas públicas adequadas à realização dos direitos humanos das mulheres. Essas dificuldades aparecem, sobretudo, na efetivação de leis como a Maria da Penha, um dos mais importantes avanços jurídicos realizados na América Latina, mas que demanda a existência de uma justiça mais célere e de mecanismos efetivos de proteção às mulheres, que resolvem denunciar os abusos, a violência doméstica e a exploração sexual.

Em síntese, como o artigo procurou destacar, as mudanças necessárias não são apenas jurídicas ou políticas. Elas são, sobretudo, culturais e demandam um esforço contínuo de articulação, de fiscalização e de atuação dos movimentos sociais e das ONGs de mulheres. Somente com esse esforço será possível obter cada vez mais avanços na realização dos Direitos Humanos das mulheres no Brasil, conforme demonstram os exemplos práticos de avanços apresentados neste artigo, como a Lei Maria da Penha e a criação da Secretaria Especial de Políticas para as Mulheres.

\section{REFERÊNCIAS.}

ALI, Shaheen Sardar. Conceptualising Islamic Law, CEDAW and Women's Human Rights in Plural Legal Settings: A Comparative Analysis of Application of CEDAW in Bangladesh, India and Pakistan. Unifem-South Asia Regional Office, January, 2006.

BOHN, Simone. Feminismo estatal sob a presidência Lula: O caso da Secretaria de Políticas Para as Mulheres. Revista Debates, Porto Alegre, v. 4, n. 2, p. 81106, 2010.

BUNCH, Charlotte. Women's Rights as Human Rights: Toward a Re-Vision of Human Rights. Human Rights Quarterly, v. 12, n. 4, p. 486-498, nov., 1990. 
BYRNES, Andrew. The Committee on the Elimination of Discrimination against Women. In: HELLUM, Anne \& AASEN, Henriette Sinding. Women's Human Rights: CEDAW in International, Regional and National Law. Cambridge: Cambridge University Press, 2013, p. 27-61.

BRASIL. Presidência da República. Secretaria Especial de Políticas para as Mulheres. Il Plano Nacional de Políticas para as Mulheres. Brasília: Secretaria Especial de Políticas para as Mulheres, 2008, 236 p.

BRASIL. Secretaria Especial de Políticas para as Mulheres. Convenção para a Eliminação de todas as Formas de Discriminação contra a Mulher - CEDAW. 2010. Disponível em: goo.gl/r3rm9x; Acesso em: 29 de dezembro de 2016.

BRASIL. Presidência da República. Secretaria Especial de Políticas para as Mulheres. Plano Nacional de Políticas para as Mulheres. Brasília: Secretaria de Políticas para as Mulheres, 2013. Disponível em: https://goo.gl/8fWW9q. Acesso em: 04/07/2017.

BRASIL. Presidência da República. Secretaria Especial de Políticas para as Mulheres. Relatório Anual Socioeconômico da Mulher. Brasília: Secretaria de Políticas para as Mulheres, março de 2015, 181 p.

COOK, Rebecca J. Introduction: Women's International Human Rights Law: The Way Forward. In: COOK, R. (ed.). Human Rights of Women: National and International Perspectives. Philadelphia: University of Pennsylvania Press, 1994.

DAIRIAM, Shanthi. Impact of the convention at the domestic level. 2004. Disponível em: goo.gl/P7k8kN. Acesso em: 20 de abril de 2017.

DÍAZ, Capitolina. The CEDAW: How a Cold War Product Could Become a Key Instrument for Women's Rights in the Global Society. XVII ISA World Congress of Sociology, 2014.

DONNELLY, Jack. International Human Rights: A Regime Analysis. International Organization, v. 40, n. 3, p. 599-642, 1986.

EVATT, Elizabeth. Finding a Voice for Women's Rights: The Early Days of CEDAW. The George Washington International Law Review, v. 34, n. 3, p. 515$553,2002$.

HELLUM, Anne \& AASEN, Henriette Sinding. Introduction. In: HELLUM, Anne \& AASEN, Henriette Sinding. Women's Human Rights: CEDAW in International, Regional and National Law. Cambridge: Cambridge University Press, 2013, p. 124. 
IBGE. Estatísticas de gênero: uma análise dos resultados do censo demográfico 2010. Rio de Janeiro. 2014. Disponível em: https://goo.gl/PYhCyQ. Acesso em: 04/07/2017. KRASNER, Stephen D. Causas estruturais e consequências dos regimes internacionais: regimes como variáveis intervenientes. Rev. Sociol. Polit., Curitiba, v. 20, n. 42, p. 93-110, 2012.

MERRY, Sally Engle. Human Rights and Gender Violence: Translating International Law into Local Justice. Chicago: University of Chicago Press, 2009.

MIGUEL, Luis Felipe. Teoria política feminista e liberalismo: o caso das cotas de representação. Revista Brasileira de Ciências Sociais, São Paulo, v. 15, n. 44, p. 91-102, 2000.

MIRANDA, C. M. Os movimentos feministas e a construção de espaços institucionais para a garantia dos direitos das mulheres no Brasil e no Canadá. Anais Eletrônicos do IX Encontro da Associação Brasileira de Ciência Política, Brasília: ABCP, 2014, p. 1-15.

OHCHR. Status Of Ratification Interactive Dashboard. 2016. Disponível em: http://indicators.ohchr.org. Acesso em: 28 de dezembro de 2016.

PIMENTEL, Silvia. Education and Legal Literacy. In: SCHÖPP-SCHILLING, Hanna Beate e FLINTERMAN, Cees. (eds.). The Circle of Empowerment: Twenty-Five Years of the UN Committee on the Elimination of Discrimination against Women. New York: Feminist Press at the City University of New York, 2007, $410 \mathrm{p}$.

PIMENTEL, Silvia Carlos da Silva; PIOVESAN, Flávia. A Lei Maria da Penha na perspectiva da responsabilidade internacional do Brasil. In: CAMPOS, Carmen Hein de. (Org.). Lei Maria da Penha comentada em uma perspectiva jurídicofeminista. Porto Alegre: Lumen Juris Editora, 2011.

RIGGIN, Jessica. The Potential Impact of CEDAW Ratification on U.S. Employment

Discrimination Law: Lessons From Canada. Columbia Human Rights Law Review, v. 42, n. 2, p. 541-611, 2011.

SCHÖPP-SCHILLING, Hanna Beate. The Nature and Scope of the Convention. In: SCHÖPP-SCHILLING, Hanna Beate e FLINTERMAN, Cees. (eds.). The Circle of Empowerment: Twenty-Five Years of the UN Committee on the Elimination of Discrimination against Women. New York: Feminist Press at the City University of New York, 2007, 410 p. 
SHIN, Heisoo. CEDAW and Women's Human Rights: Achievements and Obstacles. Paper presented at Human Rights Law's Annual Conference. Human Rights 2004: The Year in Review. Castan Center for Human Rights, Law's Annual Conference. Monash University, 3 December 2004.

SPOHR, Alexandre Piffero; MAGLIA, Cristiana; MACHADO, Gabriel; OLIVEIRA, Joana Oliveira de. Participação política de mulheres na América Latina: $O$ impacto de cotas e de lista fechada. Estudos Feministas, v. 24, n. 2, p. 417$441,2016$.

UNITED NATIONS. Report on the working methods of the human rights treaty bodies relating to the state party reporting process. 2011. Disponível em: http://www.bayefsky.com/methods/hri_icm_2011_4.pdf. Acesso em: 20 de abril de 2017.

UN WOMEN. Convention on the Elimination of all Forms of Discrimination against Women. Disponível em: http://www.un.org/womenwatch/daw/cedaw/reservations; Acesso em: 20 de abril de 2017.

VERDIRAME, Guglielmo. The UN and Human Rights: Who Guards the Guardians? Cambridge: Cambridge University Press, 2011.

YOUNG, Oran R. Compliance and Public Authority: A Theory with International Applications. Baltimore: Johns Hopkins University Press, 1979.

WAISELFISZ J.J. Mapa da violência 2015. Homicídio de mulheres no Brasil.. Brasília: Secretaria-Geral da Presidência da República; Secretaria Nacional de Juventude; Secretaria de Políticas de Promoção da Igualdade Racial, 2015. Disponível em: https://goo.gl/4IMkbA. Acesso em: 04/07/2017.

YOUNG, Oran R. Regime Dynamics: The Rise and Fall of International Regimes. International Organization, v. 36, n. 2, p. 277-297, 1982.

YOUNG, Oran R. International Cooperation - Building Regimes for Natural Resources and the Environment. Ithaca: Cornell University Press, 1989.

Recebido em 24 de abril de 2017. Aprovado em 23 de agosto de 2017. 